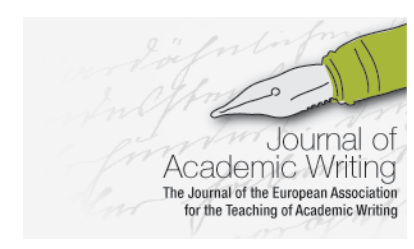

\title{
Editorial
}

\section{Developing the Writer: Strategies, Behaviours, Peer Reviewing and Precision}

Welcome to the Summer 2021 issue of the Journal of Academic Writing. Writing a year and a half into the coronavirus pandemic, academia has experienced numerous impacts globally. JoAW has of course experienced these impacts too and we are extremely grateful to everyone who has contributed to sustaining the journal's operations and standards during these trying times - our editors and reviewers, our copy-editors and proof-readers, and of course the authors who have worked patiently with us while we see their work through our publication processes.

This general issue gathers research articles that have accrued in our Issue in Progress over 2020, along with two new papers received more recently. We are also pleased to share three book reviews to complement the issue, edited by Mark Carver, and we are grateful to Mark for also stepping up to support general editorial processes during lockdown. One further major change to the journal remains to be announced: I will be stepping down from editing after this issue and passing management of JOAW into the very capable hands of Niall Curry.

The articles in the Summer 2021 issue reflect the diverse interests of researchers and teachers involved in developing academic writing at different levels, from undergraduate studies in English as the medium of instruction to doctoral research writing and peer reviewing exchanges, with forays into formative assessment practices and issues of comfort with writing in STEM subjects. Underlying the research is a marked move toward selectively and effectively developing and empowering writers in the disciplines; hence this issue speaks to studentcentred writing pedagogies.

To begin, the issue opens with two complementary articles exploring strategies for improving doctoral research writing circles, with implications for deep-level revision processes. Kathrin Kaufhold and Daniel Egil Yencken's investigation into the dialogic nature of writing circles lays the ground for raising the quality and effectiveness of doctoral writing groups through betterinformed facilitation of conversations.

Roger Yallop and Djuddah Leijen's investigation into the use of cover letters to support doctoral peer reviewing exchanges extends the focus on improving the effectiveness of such writing circles. Stemming from Yallop's completed doctoral research, the article's exploration of the effectiveness of cover letters bears relevance for all peer-to-peer reviewing practices supporting writing development, and not just at doctoral levels.

Three articles offer perspectives on effective writing development for students located in English for Academic Purposes (EAP) contexts. Diana Mazgutova and Judith Hanks examine students' perceptions of changes in their use of writing strategies on an intensive EAP course. The results of their study indicate the value of developing learners' understanding of writing strategies in intensive learning contexts, thereby developing the writer over the writing.

Tetyana Mueller-Lyaskovets and Olena Horner's contribution meanwhile explores the use of formative assessment to shift learners' attention from writing products to writing processes. Assessing the impact of their design on English as a Foreign Language (EFL) learners, the authors identify the importance of formative assessment for improving students' confidence and motivation to learn. In both articles, a student-centred focus equips students with the confidence to engage with deeper-level textual revisions in EFL and EAP learning environments. 
To complement the theme of EAP learner development, Marcus Bridle's contribution explores learner accuracy in a pre-sessional course. Bridle argues in favour of incorporating micro-level textual instruction into pre-sessional courses for new students. In line with Joan Turner's (2004) reasoning, the article makes the case for preserving some focus on writing proficiency given the long-term benefit of growing students' capacity for communicating disciplinary knowledge effectively.

The final article in the general issue by Justin Nicholes explores the issue of comfort in STEM writing, comparing students' feelings of belonging through their different disciplinary writing expectations. Through the study's comparison of comfort in writing in numbers, about numbers and in STEM in general, Nicholes exposes a valuable correlation between disciplinary writer identities and positive emotional experiences. The study opens many avenues for further research into how writers become comfortable with their disciplinary identities, not just in STEM writing, but in other disciplines as well.

To complement these articles, the issue carries three book reviews. The first by Christina Elizabeth Healey, examines Adrian Wallbank's Academic Writing and Dyslexia: A Visual Guide to Writing at University. Healey's explicit position as a dyslexic tutor and writer makes for an engaging first-hand account of the book's usefulness. In terms of the visual approaches Wallbank shares, Healey notes none are fool proof for all dyslexic writers with some needing support from tutors, while others could well be applied immediately by students. Yet the generosity of the book in championing differences speaks again to the student-centred pedagogies underpinning this issue.

Jenifer Spencer's review of Science Communication appraises a new entry into an already rich niche of handbooks. The book's logical contextualisation of science writing within public discourse speaks to Spencer's experiences of the pandemic, and the mediation of scientific knowledge through political discourse. While Science Communication overlooks the specific issue of English as the lingua franca for scientific research communication, Spencer notes its value for EAP and translation department teaching, invoking an interesting parallel with Nicholes' article examining disciplinary comfort and belonging.

The final review does speak to the issue of uneven global research dissemination and English as the lingua franca for research. Jean Matier Moore, a South African scholar, reviews a text firmly located in writing centre networks in South Africa. With its chapter reflecting on what American - and, undoubtedly, European, and global - writing centres can learn from the experiences of South Africa's multilingual context, the book's value to writing centres globally is well-argued. Yet the difficulty of raising visibility of such texts in Western networks is an ongoing challenge and JoAW is pleased to be able to share Moore's perspective.

Conditions during the coronavirus pandemic have been challenging and many colleagues have reported intensified workloads and increased stress, for themselves and their students. The rapid shift to online contexts has created numerous pressures and exposed global and national systemic fragilities, in academia as much as in welfare, health systems and beyond. And so, I close this editorial with good wishes for your health, your resilience and wellbeing during these trying times.

George Ttoouli

Coventry University, UK 


\section{References}

Turner, J. (2004). Language as academic purpose. Journal of English for Academic Purposes, 3, 95-109. https://doi.org/10.1016/S1475-1585(03)00054-7 